\title{
Seeing pre-screened, regular clients associated with lower odds of workplace sexual violence and condom refusal amidst sex work criminalization: Findings of a community-based cohort of sex workers in Metro Vancouver, Canada (2010-2019)
}

\section{Bronwyn McBride}

Centre for Gender and Sexual Health Equity

Kate Shannon

Centre for Gender and Sexual Health Equity

Jennie Pearson

Centre for Gender and Sexual Health Equity

\section{Andrea Krüsi}

Centre for Gender and Sexual Health Equity

Melissa Braschel

Centre for Gender and Sexual Health Equity

Shira Goldenberg ( $\sim$ dr.goldenberg@cgshe.ubc.ca )

San Diego State University

\section{Research Article}

Keywords: sex work, sex work clients, condom use, HIV prevention, HIV/STIs, end-demand

Posted Date: October 21st, 2021

DOl: https://doi.org/10.21203/rs.3.rs-959373/v1

License: (c) (i) This work is licensed under a Creative Commons Attribution 4.0 International License. Read Full License

Version of Record: A version of this preprint was published at BMC Public Health on March 17th, 2022. See the published version at https://doi.org/10.1186/s12889-022-12903-9. 


\section{Abstract \\ Background}

Research that accurately represents how characteristics of sex work clients relate to sex workers' labour conditions is crucial for informing evidence-based legislation which upholds sex workers' human rights. However, little quantitative research has examined how seeing regulars (repeat clients) impacts sex workers' occupational safety, particularly under 'end-demand' criminalization.

\section{Methods}

Drawing on longitudinal data from a community-based cohort of 900+ sex workers in Vancouver, we used logistic regression analyses to 1) describe correlates of seeing mostly pre-screened, regular clients, 2) identify associations between seeing mostly regulars and odds of experiencing occupational outcomes of workplace sexual violence and client condom refusal, and 3) examine the interaction between seeing mostly regulars and work environment on workplace sexual violence and client condom refusal.

\section{Results}

Over the 9-year study ( $\mathrm{N}=925)$, seeing mostly regulars was associated with reduced odds of sexual violence (AOR $0.73,95 \% \mathrm{Cl} 0.53-1.02$ ) and client condom refusal (AOR $0.70,95 \% \mathrm{Cl} 0.57-0.86$ ) in multivariable GEE confounder models. These associations were strongest among sex workers in outdoor/informal indoor workspaces.

\section{Conclusion}

Our findings highlight protective effects of seeing pre-screened regulars within a criminalized setting. Removal of 'end-demand' client criminalization is needed to enable sex workers to effectively screen clients, support HIV/STI prevention, and advance sex workers' human rights.

\section{Background}

Research that accurately represents characteristics of sex work clients and how these relate to sex workers' labour conditions is crucial for informing evidence-based sex work legislation, which is a wellestablished determinant of sex workers' occupational health and human rights(1-3). While individuals who purchase sex services are commonly represented in policy discourse as violent, exploitative, and contributors to HIV (human immunodeficiency virus)/STI (sexually transmitted infection) burden, a broadening body of evidence has highlighted the criminalization of aspects of sex work as a major determinant structuring sex worker and client interactions, with impacts on condom use negotiation and sex workers' exposure to workplace violence(4-8). Amid prominent stereotypes of sex work clients as 
coercive and/or violent and a wave of 'end-demand' approaches to sex work legislation(9), purchasing sex services is currently criminalized in 75 countries globally(10). However, particularly in North America and many European countries where end-demand laws have been implemented, evidence on the implications of seeing mostly regular clients (pre-screened, repeat clients) on sex workers' occupational safety remains limited.

Existing literature shows that client-sex worker interactions are shaped by structural determinants (i.e., laws, policies), work environment factors (i.e., outdoors vs. various indoor spaces, working alone vs. with colleagues or a manager), and interpersonal factors (i.e., gendered power dynamics, patriarchal ideologies, racism)(11-16). Qualitative studies have documented diverse client-sex worker dynamics in terms of occupational health issues such as workplace violence and condom use(11, 13, 17-20). In research conducted in Asia and sub-Saharan Africa, repeat visits and greater relationship intimacy between sex workers and regular clients have been associated with lower condom use(16, 21-23). However, limited epidemiological research has explored the implications of seeing regular clients on condom use negotiation among sex workers in global northern contexts such as Canada. This gap is particularly salient under laws implemented in 2014 which criminalized purchasing sex services for the first time in Canadian history, and amid the COVID-19 pandemic as many sex workers are limiting the number of clients they see $(24,25)$.

In the 1990s, North American criminal justice institutions began to shift focus from targeting sex workers towards targeting clients with the aim of discouraging men from seeking sex services(26). The "enddemand" legislative model (Nordic/abolitionist model) was first implemented in Sweden in 1999(27), and subsequently in Norway, Iceland, France and several other countries(9). Based on ideologies depicting sex workers as victims and clients as abusers who exploit vulnerable women (including through coercing condomless sex), end-demand laws typically criminalize the purchase of sex(27), while leaving the sale of sex legal to lessen the criminalization of sex workers. However, criminalizing any aspect of sexual service exchange can impact occupational health including sexual health and HIV/STI exposure in sex worker-client interactions, as punitive policing has been robustly documented to push sex workers and clients into isolated settings, increase workers' vulnerability to violent perpetrators, and limit their negotiating power for condom use $(3,8,14,28-30)$. Concerningly, limited research from Sweden and France suggests that end-demand laws undermine sex workers' ability to screen new clients (the process of collecting client information, vetting clients, and establishing boundaries, services offered, prices, and use of personal protective equipment), as clients fear providing identifying information due to the potential consequences of criminalization(29, 31-33). End-demand laws have also been shown to undermine condom use negotiation, enhance exposure to workplace violence, and heighten barriers to voluntary HIV/STI testing $(29,31,32)$.

In Canada, end-demand legislation was enacted in December 2014(34) after the Supreme Court declared the previous sex work laws unconstitutional for violating sex workers' rights to security of person(35). This legislation explicitly criminalizes the purchase of sex services in all circumstances, and also criminalizes third parties (i.e., venue owners/managers, security) who gain material benefits from others' 
sex work(36). Concerningly, research suggests that Canadian end-demand laws reproduce the unsafe labour conditions of the previous unconstitutional legislation(37,38). A qualitative study in Vancouver found that police targeting clients of street-based sex workers undermined sex workers' existing client screening and safety strategies, heightened their exposure to violence, and disrupted relationships with their pre-screened regular clients(14). Amid end-demand criminalization and COVID-19, as the BC Centre for Disease Control recommended that sex workers see fewer clients more frequently as a safety strategy(39), epidemiological research on sex workers' interactions with regular clients and how this shapes occupational health and safety outcomes is urgently needed.

Study objectives

Drawing on a structural determinants of HIV framework(1), we used prospective cohort data collected over a 9-year study period to 1) describe correlates of seeing mostly pre-screened, regular clients, 2) identify independent associations between seeing mostly regulars and odds of experiencing occupational outcomes of workplace sexual violence and client condom refusal, and 3) examine the interaction between seeing mostly regulars and work environment on workplace sexual violence and client condom refusal, over 9 years.

\section{Methods}

Longitudinal data were drawn from a community-based open prospective cohort, An Evaluation of Sex Workers Health Access (AESHA) which initiated recruitment in 2010 and is based on community collaborations since 2005. Eligibility criteria at baseline include identifying as a cisgender or transgender woman, having exchanged sex for money in the last month, aged 14+, and able to provide written informed consent. Time-location sampling supported recruitment through daytime and late-night outreach to diverse outdoor (i.e., streets, alleys), indoor settings (i.e., massage parlours, micro-brothels, hotels, bars) and online solicitation spaces across Metro Vancouver. Since inception, current/former sex workers are hired throughout the project, from interviewers/outreach workers and sexual health research nurses to coordinators. Further detail on AESHA's community origins is available elsewhere(40).

After obtaining informed consent, participants completed questionnaires administered by a trained interviewer in English, Cantonese or Mandarin at baseline and semiannual follow-up visits. The questionnaire elicited responses on socio-demographics, work environments, structural factors, and health access and outcomes. Interviews were conducted at study offices in Vancouver or a confidential space of participants' choice (e.g., home, work). Data are securely collected and managed using REDCap(41) electronic data capture tools hosted at the University of British Columbia. Participants receive voluntary HIV/STI/HCV (hepatitis $\mathrm{C}$ virus) serology testing by a project nurse and are offered treatment onsite, if needed, for symptomatic STIs and Papanicolaou testing, regardless of enrolment in the study. All participants received \$40 CAD at each biannual visit. The study holds ethical approval through Providence Health Care/University of British Columbia and Simon Fraser University Research Ethics Boards. 


\section{Primary variable and outcomes}

This study used a time-updated, binary measure of seeing mostly pre-screened, regular clients, defined as participants reporting that $>75 \%$ of their clients in the last six months were repeat clients. Those for whom $\leq 75 \%$ of their clients were repeat clients were coded as not seeing mostly regulars. This was used as the outcome variable in Objective 1, and as the primary exposure of interest in Objectives 2 and 3. Time-updated occupational health and safety outcomes of interest included (1) workplace sexual violence (defined as sexual assault or rape in the context of work, perpetrated by aggressors posing as clients) and (2) client condom refusal (defined as being coerced into oral/vaginal/anal sex without a condom by any client) in the last six months.

\section{Independent variables}

Drawing on a structural determinants framework(1), independent variables at individual and structural levels were explored. Time-fixed variables included race (white, Indigenous, or woman of colour [i.e., Black, Asian, Latina]) and high school completion (vs. less than high school). All other variables were time-updated at each semiannual follow-up, examining events during the past six months or current measures at the study visit. Individual factors included age, non-injection drug use (e.g., cocaine, crystal meth; excluding cannabis and alcohol use), and injection drug use.

Structural determinants included migration (migrated within the past 5 years, migrated over 5 years ago, or Canadian-born), housing (unstable housing, defined as any stays in single-room occupancy hotels/supportive housing or staying with family/friends; homelessness), and income (average weekly income from sex work; financially supporting dependents). Work environment included primary place serving clients (informal indoor space [e.g., apartment, hotel, client's place], formal indoor venue [e.g., managed, in-call establishment such as a massage parlour], or outdoor/public space [e.g., street, car]); and average number of clients per month.

Policing measures included being arrested while working; and facing police harassment while working (police raid, police parked nearby/drove by repeatedly, told to move on, threatened with arrest/detainment/fines, being searched/followed/picked up and driven elsewhere to work, verbally harassed, detained, physically assaulted, drugs/drug use equipment confiscated, searched for condoms/condoms taken, other property taken, or propositioned to exchange sex/coerced into providing sexual favours). Health measures included facing any barriers to health care (e.g., long wait times, health insurance barriers, poor treatment by health care professionals) and having had an HIV test (vs. no test vs. living with HIV). Lastly, we evaluated exposure to the time period surrounding implementation of Canadian end-demand legislation (2010-2013 vs. 2015-2017). As the end-demand bill was introduced in January 2014 and passed into law in December 2014, this time period was excluded from all analyses due to potential variation in law enforcement. The first three months of 2015 were also excluded to account for outcome measures referring to the preceding six months. Additionally, as not all participants 
do sex work at every follow-up visit, analyses were restricted to observations where participants did sex work in the last six months.

Objective 1: Correlates of seeing mostly pre-screened regular clients

For objective 1, we examined baseline descriptive statistics for explanatory variables stratified by the outcome of seeing mostly pre-screened, regular clients. Frequencies and proportions were calculated for categorical variables and measures of central tendency and dispersion (i.e., mean, median, interquartile range (IQR)) for continuous variables. Differences were assessed using the Wilcoxon rank-sum test for continuous variables and Pearson's chi-square test (or Fisher's exact test for small cell counts) for categorical variables. We then conducted bivariate and multivariable logistic regression using generalized estimating equations (GEE) and an exchangeable correlation matrix to account for repeated measures on the same participants. Variables significantly associated with seeing mostly regulars at $p<0.10$ and those hypothesized to be associated a priori were considered for inclusion in the multivariable explanatory model. The best fitting multivariable model, as indicated by the lowest quasi-likelihood under the independence model criterion, was determined using a backward stepwise selection process. All analyses were performed in SAS version 9.4 (SAS, Cary, NC) and all p-values are two-sided.

Objective 2: Independent associations between seeing mostly regulars and odds of experiencing workplace sexual violence and client condom refusal

For objective 2, we constructed two separate multivariable GEE confounder models to assess the independent associations between seeing mostly pre-screened regulars and odds of experiencing (1) workplace sexual violence and (2) client condom refusal, in the last 6 months. Variables from the best fitting multivariable explanatory model for seeing mostly regulars were considered potential confounders. The most parsimonious models were determined using the process described by Maldonado and Greenland(42), in which potential confounders were removed in a stepwise manner, and variables that altered the association of interest by $<5 \%$ were systematically removed from the model.

Objective 3: Interaction between seeing mostly regulars and work environment on workplace sexual violence and client condom refusal

For objective 3, we developed an additive interaction variable between seeing mostly pre-screened regular clients and work environment (primary place serving clients), which was time-updated to capture events in the last six months at each visit. For this sub-analysis, work environment was examined as a binary variable (formal indoor venues vs. outdoor or informal indoor space) for ease of interpretation and statistical power. The additive interaction variable included four categories: saw mostly regular clients in a formal indoor venue, did not see mostly regulars in a formal indoor venue, saw mostly regular clients in an outdoor/public or informal indoor space, and did not see mostly regular clients in an outdoor/public or informal indoor space (the reference category). We constructed two separate multivariable GEE confounder models to examine the additive interaction between seeing mostly regulars and work environment on occupational outcomes of (1) workplace sexual violence and (2) client condom refusal. 
Potential confounders identified in Objective 2 were included in the full multivariable models. As above, variables that altered all of the associations of interest by $<5 \%$ were systematically removed from the model.

\section{Results}

Objective 1: Correlates of seeing mostly pre-screened regular clients

Analyses included 4045 observations amongst 925 sex workers between Jan 2010 - Feb 2019. Over the 9-year study, 20.9\% (193) experienced 282 events of workplace sexual violence and $40.2 \%$ (372) faced 702 events of client condom refusal. At baseline, $37.8 \%$ of participants primarily served clients in outdoor/public spaces, $29.3 \%$ in informal indoor spaces (e.g., apartment, hotel, client's place), and 30.8\% in formal indoor venues (e.g., massage parlours). 31.2\% (289) had experienced recent police harassment while working. Baseline descriptive statistics are presented in Table I.

Table I: Baseline individual and structural factors stratified by seeing mostly regular clients among sex workers in Metro Vancouver ( $\mathrm{n}=925)$, AESHA 2010-2019 


\begin{tabular}{|c|c|c|c|c|}
\hline \multirow[t]{3}{*}{ Characteristic } & \multirow{3}{*}{$\begin{array}{l}\text { Total } \\
(N=925) \\
\text { n (\%) }\end{array}$} & \multicolumn{2}{|c|}{ Saw mostly regular clients ${ }^{\dagger}$} & \multirow[t]{3}{*}{$P$} \\
\hline & & \multirow{2}{*}{$\begin{array}{l}\text { Yes ( } N=228) \\
n(\%)\end{array}$} & \multirow{2}{*}{$\begin{array}{l}\text { No } \\
(\mathrm{N}=697) \\
\mathrm{n}(\%)\end{array}$} & \\
\hline & & & & \\
\hline \multicolumn{5}{|l|}{ Individual factors } \\
\hline Age, median (IQR) & $35(28-42)$ & $36(29.5-43)$ & $35(28-42)$ & 0.059 \\
\hline Completed high school & $514(55.6)$ & $132(57.9)$ & $382(54.8)$ & 0.415 \\
\hline Non-injection drug use ${ }^{\dagger}$ & $615(66.5)$ & $168(73.7)$ & $447(64.1)$ & 0.007 \\
\hline Injection drug use ${ }^{\dagger}$ & $374(40.4)$ & $102(44.7)$ & $272(39.0)$ & 0.127 \\
\hline \multicolumn{5}{|l|}{ Structural determinants } \\
\hline \multicolumn{5}{|l|}{ Time since im/migration* } \\
\hline Non-im/migrant & $659(71.2)$ & $183(80.3)$ & $476(68.3)$ & \\
\hline $\mathrm{Im} /$ migrated $\leq 5$ years ago & $99(10.7)$ & $6(2.6)$ & $93(13.3)$ & \\
\hline $\mathrm{Im} /$ migrated $>5$ years ago & $147(15.9)$ & $35(15.4)$ & $112(16.1)$ & $<0.0001$ \\
\hline \multicolumn{5}{|l|}{ Race } \\
\hline White & $288(31.1)$ & $78(34.2)$ & $210(30.1)$ & \\
\hline Indigenous & $354(38.3)$ & $107(46.9)$ & $247(35.4)$ & \\
\hline Woman of colour & $283(30.6)$ & $43(18.9)$ & $240(34.4)$ & $<0.0001$ \\
\hline \multicolumn{5}{|l|}{ Housing \& income } \\
\hline Any unstable housing ${ }^{\dagger}$ & $728(78.7)$ & $194(85.1)$ & $534(76.6)$ & 0.004 \\
\hline Homeless/living on street $^{\dagger}$ & $279(30.2)$ & $69(30.3)$ & $210(30.1)$ & 0.981 \\
\hline $\begin{array}{l}\text { Average weekly income from sex } \text { work }^{\dagger} \\
(\text { (SCAD), median (IQR) }\end{array}$ & $\begin{array}{l}500(250- \\
1000)\end{array}$ & $\begin{array}{l}500(200- \\
1000)\end{array}$ & $\begin{array}{l}500(270- \\
1000)\end{array}$ & 0.028 \\
\hline Currently financially supports dependents & $277(30.0)$ & $78(34.2)$ & $199(28.6)$ & 0.105 \\
\hline \multicolumn{5}{|l|}{ Work environment } \\
\hline \multicolumn{5}{|l|}{ Primary place serving clients ${ }^{\dagger}$} \\
\hline Outdoor/public space & $350(37.8)$ & $74(32.5)$ & $276(39.6)$ & \\
\hline Informal indoor space & $271(29.3)$ & $105(46.1)$ & $166(23.8)$ & \\
\hline Formal indoor venue & $285(30.8)$ & $41(18.0)$ & $244(35.0)$ & $<0.0001$ \\
\hline
\end{tabular}




\begin{tabular}{|c|c|c|c|c|}
\hline \multirow[t]{4}{*}{ Characteristic } & \multirow{4}{*}{$\begin{array}{l}\text { Total } \\
(N=925) \\
\mathrm{n}(\%)\end{array}$} & \multicolumn{2}{|c|}{ Saw mostly regular clients ${ }^{\dagger}$} & \multirow[t]{4}{*}{$P$} \\
\hline & & \multirow{3}{*}{$\begin{array}{l}\text { Yes (N=228) } \\
n(\%)\end{array}$} & \multirow{3}{*}{$\begin{array}{l}\text { No } \\
(\mathrm{N}=697) \\
\mathrm{n}(\%)\end{array}$} & \\
\hline & & & & \\
\hline & & & & \\
\hline Average \# of clients/month ${ }^{\dagger}$; median (IQR) & $40(20-80)$ & $32(10-60)$ & $48(24-80)$ & $<0.0001$ \\
\hline Client condom refusal $^{\dagger}$ & $193(20.9)$ & $44(19.3)$ & $149(21.4)$ & 0.562 \\
\hline \multicolumn{5}{|l|}{ Violence \& policing } \\
\hline Workplace sexual violence ${ }^{\dagger}$ & $101(10.9)$ & $23(10.1)$ & $78(11.2)$ & 0.644 \\
\hline Police harassment while working ${ }^{\dagger}$ & $289(31.2)$ & $60(26.3)$ & $229(32.9)$ & 0.063 \\
\hline Arrested/jailed while working $^{\dagger}$ & $53(5.7)$ & $12(5.3)$ & $41(5.9)$ & 0.724 \\
\hline \multicolumn{5}{|l|}{ Health } \\
\hline Experienced any barriers to health care ${ }^{\dagger}$ & $604(65.3)$ & $150(65.8)$ & $454(65.1)$ & 0.857 \\
\hline \multicolumn{5}{|l|}{ HIV testing $^{+}$} \\
\hline Did not have an HIV test & $393(42.5)$ & $87(38.2)$ & $306(43.9)$ & \\
\hline Had an HIV test & $363(39.2)$ & $88(38.6)$ & $275(39.5)$ & \\
\hline Living with HIV & $131(14.2)$ & $46(20.2)$ & $85(12.2)$ & 0.011 \\
\hline $\begin{array}{l}\text { All data refer to } n(\%) \text { of participants unless } \\
{ }^{\dagger} \text { In the } 6 \text { months } \\
\text { *immigrant or migrant; inclusive of any imm }\end{array}$ & erwise specit & & & \\
\hline
\end{tabular}

Over half of participants $(57.3 \%, n=530)$ saw mostly pre-screened regulars at some point, with 1676 events of seeing mostly regulars over the 9-year study. In multivariable GEE analysis, participants who faced homelessness, those who used non-injection drugs, and those working in formal indoor venues (e.g., massage parlours, vs. on the street/in public) had lower odds of seeing regulars (Table II). Older participants and those working in informal indoor settings (e.g., apartments, vs. on the street/in public) had higher odds of seeing regulars. Participants had a 1.6-fold increased odds of seeing mostly prescreened regulars (not fewer clients, but a greater proportion of pre-screened clients) after the implementation of end-demand legislation.

Table II: Correlates of seeing mostly regular clients among sex workers in Metro Vancouver $(n=925)$, AESHA 2010-2019 


\section{Characteristic}

Odds Ratio (95\%

Cl)

Adjusted Odds Ratio (95\%

Cl)

\section{Individual factors}

Age (per year older)

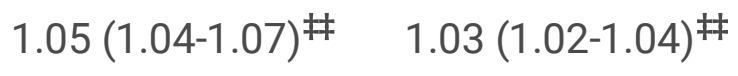

Non-injection drug use ${ }^{\dagger}$

$0.91(0.76-1.08) \quad 0.83(0.68-1.02)$ **

Completed high school

$0.91(0.74-1.11)$

\section{Structural determinants}

Race

White

ref

Indigenous

$1.08(0.86-1.37)$

Woman of colour

$0.43(0.33-0.58)^{\#}$

Time since im/migration

Non-im/migrant

ref

$\mathrm{Im} /$ migrated $\leq 5$ years ago

$0.24(0.16-0.38)^{\#}$

$\mathrm{Im} /$ migrated $>5$ years ago

$0.49(0.37-0.65)^{\#}$

Housing \& income

Any unstable housing ${ }^{\dagger}$

$1.02(0.86-1.21)$

Homeless/living on street ${ }^{\dagger}$

$0.60(0.50-0.72)^{\#}$

$0.77(0.65-0.92)^{\#}$

Average weekly income from sex work ${ }^{\dagger}$ (per $\$ 100$ CAD)

Currently financially supports dependents

$0.94(0.92-0.95)^{\#}$

$1.12(0.95-1.31)$

Work environment

Primary place serving clients ${ }^{\dagger}$

Outdoor/public space

Ref

ref

Informal indoor space

$3.37(2.82-4.02) \#$

$2.96(2.48-3.52) \#$

Formal indoor venue

$0.73(0.55-0.96)^{\#}$

$0.56(0.41-0.78)^{\#}$

Average number of clients/month ${ }^{\dagger}$ (per client)

Any inconsistent condom use ${ }^{\dagger}$

0.99 (0.98-0.99) \#

$0.76(0.62-0.93)^{\#}$ 


\section{Characteristic}

Odds Ratio (95\%

Cl)

Adjusted Odds Ratio (95\%

Cl)

\section{Violence \& policing}

Police harassment while working ${ }^{\dagger}$

$0.57(0.48-0.68)^{\#}$

Arrested/jailed while working ${ }^{\dagger}$

$0.54(0.33-0.89)^{\#}$

Health

Experienced any barriers to health care ${ }^{\dagger}$

$0.89(0.78-1.01)$

HIV testing ${ }^{\dagger}$

Did not have an HIV test

ref

Had an HIV test

$0.79(0.66-0.93)^{\#}$

Living with HIV

$1.67(1.25-2.21)^{\#}$

Interview conducted post-PCEPA

$2.00(1.72-2.32)^{\#}$

$1.58(1.35-1.85)^{\#}$

${ }^{\dagger}$ Time-updated measures (serial measures at each study visit using last 6 months as reference point)

\# Significantly associated at $p<0.05$

** Significantly associated at $p<=0.10$

* Variable was included in multivariable analysis but was not retained in the best fitting model

Objective 2: Independent associations between seeing mostly regulars and odds of experiencing workplace sexual violence and client condom refusal

In separate multivariable confounder models, seeing mostly pre-screened regulars was independently associated with significantly reduced odds of workplace sexual violence and client condom refusal (Table III) after adjusting for key confounders.

Table III: Multivariable GEE independent associations between seeing mostly regular clients and workplace sexual violence and client condom refusal among sex workers in Metro Vancouver $(n=925)$, AESHA 2010-2019 


\begin{tabular}{|c|c|c|c|c|}
\hline \multirow[t]{2}{*}{ Exposure } & \multicolumn{2}{|c|}{$\begin{array}{l}\text { Outcome: Experienced workplace } \\
\text { sexual violence }{ }^{\dagger}\end{array}$} & \multicolumn{2}{|c|}{$\begin{array}{l}\text { Outcome: Experienced client condom } \\
\text { refusal }^{\dagger}\end{array}$} \\
\hline & $\begin{array}{l}\text { Odds Ratio } \\
(95 \% \mathrm{Cl})\end{array}$ & $\begin{array}{l}\text { Adjusted Odds Ratio } \\
(95 \% \mathrm{Cl})\end{array}$ & $\begin{array}{l}\text { Odds Ratio } \\
(95 \% \mathrm{Cl})\end{array}$ & $\begin{array}{l}\text { Adjusted Odds Ratio } \\
\text { (95\% Cl) }\end{array}$ \\
\hline $\begin{array}{l}\text { Saw mostly } \\
\text { regular clients }^{\dagger}\end{array}$ & $\begin{array}{l}0.60(0.44- \\
0.81)^{\#}\end{array}$ & $0.73(0.53-1.02)^{\star \star}$ & $\begin{array}{l}0.66(0.55- \\
0.80)^{\#}\end{array}$ & $0.70(0.57-0.86)^{\#}$ \\
\hline \multicolumn{5}{|c|}{$\begin{array}{l}\text { † Time-updated measures (serial measures at each study visit using last } 6 \text { months as reference point) } \\
\text { \# Significantly associated at } p<=0.05\end{array}$} \\
\hline \multicolumn{5}{|c|}{${ }^{* *}$ Significantly associated at $p<=0.10$} \\
\hline \multicolumn{5}{|c|}{$\begin{array}{l}\text { Both models adjusted for key confounders retained in the model fitting process, including age, non- } \\
\text { injection drug use, homelessness, primary place serving clients (retained in workplace sexual violence } \\
\text { model only), and whether the interview was conducted post-end demand law reform. }\end{array}$} \\
\hline
\end{tabular}

Objective 3: Interaction between seeing mostly regulars and work environment on workplace sexual violence and client condom refusal

In multivariable GEE confounder models examining the additive interaction between seeing mostly prescreened regular clients and work environment, participants who saw mostly regulars and primarily worked in outdoor/public or informal indoor venues faced significantly lower odds of experiencing workplace sexual violence (AOR $0.69,95 \% \mathrm{Cl} 0.49-0.95$ ) and client condom refusal (AOR $0.64,95 \% \mathrm{Cl} 0.52$ -0.80 )(Table IV) relative to those who worked in the same venues and did not see mostly regulars. There was evidence of reduced odds of sexual violence and client condom refusal for sex workers who worked in formal indoor venues whether they saw mostly regulars or not, compared to those who did not see mostly regulars and worked in outdoor/public or informal indoor spaces, although the majority of these differences were not significant in multivariable analysis.

Table IV: Additive interaction between seeing mostly regular clients and work environment on workplace sexual violence and client condom refusal among sex workers in Metro Vancouver, Canada $(n=925)$, AESHA 2010-2019 


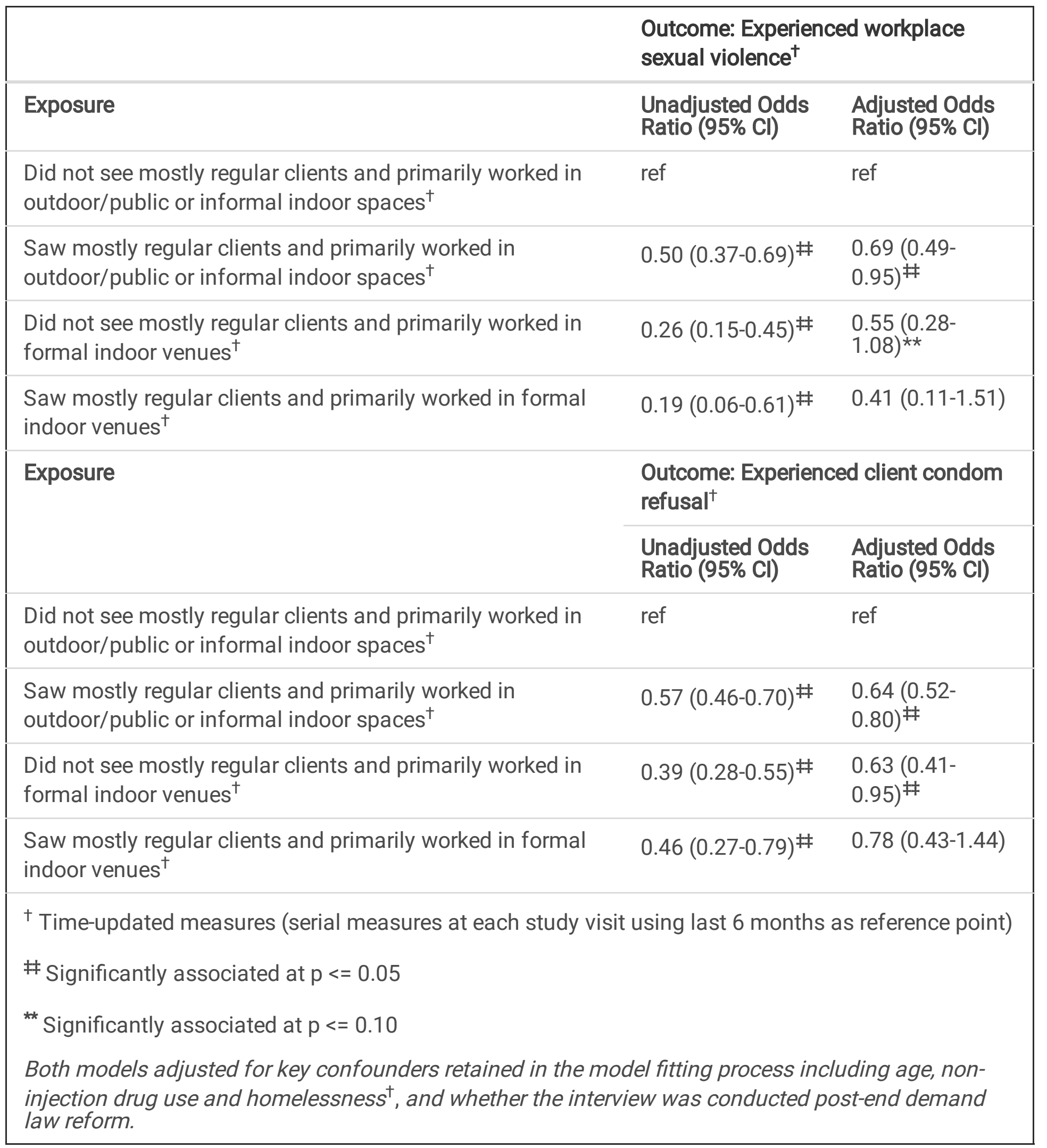

\section{Discussion}

Over this 9-year community-based cohort study involving 925 women sex workers, over half of participants $(57.3 \%)$ saw mostly regular clients at some point. Those who saw mostly pre-screened regulars had reduced odds of facing workplace sexual violence and client condom refusal, highlighting 
how sex workers' active screening and vetting of clients shapes clients' behaviour and enhances sex workers' safety and labour conditions within a criminalized context. The identified protective effect of seeing mostly regulars on sexual violence and condom refusal from our additive interaction sub-analysis was most significant among sex workers working in outdoor/informal indoor spaces. Under end-demand laws, participants had a 1.6-fold increased odds of seeing mostly pre-screened regulars (not fewer clients, but a greater proportion of pre-screened clients vs. new clients). Our findings suggest that seeing prescreened, vetted regulars represents an important occupational health and safety strategy for sex workers which is rendered even more critical amid end-demand criminalization which has been documented to undermine sex workers' ability to screen new clients $(29,32,38,44)$, and one which may be particularly salient in precarious work environments lacking the structural supports associated with formal indoor venues.

Seeing mostly regulars and diverse modes of work

In our study, sex workers who were older and worked primarily in informal indoor spaces (e.g., apartments, vs. on the street/in public) had greater odds of seeing pre-screened regulars, while noninjection drug users and those who faced recent homelessness had lower odds of seeing regulars, highlighting important class differences in sex workers' ability to see regular clients. While over half of participants saw mostly regulars at some point during the study, $42.7 \%$ reported never seeing mostly regulars, highlighting a diversity of modes of sex work. $30.8 \%$ of participants worked in formal indoor venues (e.g., massage parlours) at baseline and had reduced odds of seeing mostly regulars, which is expected as many massage parlours are street-facing venues that receive one-time and walk-in clients. Formal indoor venues can provide an established clientele (i.e., clients who routinely visit the venue, negating the need for the worker to market their services/find their own clients) and managerial support with client screening $(5,37,45-48)$ which can be particularly desirable for im/migrant women for whom language barriers and limited social capital can present challenges to independent sex work $(49,50)$. Further, prior research has shown that some sex workers prefer short client interactions due to desire for anonymity and/or not wanting to engage in emotional labour, and thus organize their work accordingly (e.g., by offering time-limited sexual services in formal indoor venues)(20,51), while others highlight romance, emotional connection and intimate conversation as services offered to clients, and thus structure their labour to enable longer-term client relationships(51). In general, our results highlight diverse approaches to client type and work environments, suggesting that policy efforts to promote sex workers' safety and sexual health including HIV/STI prevention should dismantle all restrictions which undermine sex workers' screening abilities, and enable sex workers to structure their labour and select clients according to their own preferences.

Impacts of seeing mostly regulars on client condom refusal and workplace sexual violence

Our study found that seeing mostly pre-screened regulars was associated with reduced odds of client condom refusal (coercion into any type of condomless sex) within a criminalized setting. Our findings differ in some ways from global literature: in Asia and sub-Saharan Africa, the client vs. intimate partner 
boundary has been documented to be more fluid, with implications for condom use. In the Dominican Republic(52), Madagascar(21), Uganda(53) Nepal(23) and Indonesia(22), repeat visits and greater relationship intimacy (i.e., viewing the client as more of a boyfriend) has been associated with lower condom use. However, our results align with research from western contexts where sex workers reported high rates of client condom use and minimal overlap between clients and non-paying partners. In Scotland, sex workers used condoms almost $100 \%$ of the time with clients and rarely with intimate partners(18), and a Canadian study found that $87.2 \%$ of sex workers and $90.4 \%$ of clients reported always using condoms in a sex work encounter relative to $40.1 \%$ and $8.6 \%$ always using condoms in romantic relationships, respectively(54). Given the potential for HIV/STI exposure associated with condomless sex with many partners, there is some evidence that 'hobbyists' or clients who see sex workers often are more likely to use condoms: a US study found that regular clients were more likely to be risk averse and use condoms than were new (i.e., first time or second time) sex work clients(55).

Sex workers who saw mostly pre-screened regulars also had lower odds of facing workplace sexual violence (sexual assault or rape while working). Despite prominent stereotypes positing sex buyers as violent, research suggests that male clients of sex workers generally reflect the broader population of men(56-58); and reject sexual entitlement and ideologies that provocative women are deserving of violence $(59,60)$. Our findings are consistent with evidence that sex worker-client interactions are diverse; can range from violent (in the case of aggressors posing as clients) to uneventful to mutually pleasurable $(11,59,61)$ as in other relationships and sexual interactions; and critically, highlight sex workers' agency in their work. Moving beyond traditional public health research and legislative approaches which conceptualize sex workers as passive victims facing risk of client-perpetrated violence and HIV/STIs, the association between seeing regulars and reduced odds of workplace sexual violence can also be understood as a result of client selection, screening, vetting and retention processes implemented by sex workers. Clients who are respectful of boundaries (i.e., services offered, condom use) are those able to be seen again and become regulars. Clients are typically re-vetted by sex workers at every visit, with workers actively filtering the characteristics of repeat clients, shaping decreased boundary violations (sexual violence, condom refusal) among pre-screened regulars relative to one-time clients as identified in our analyses. Applying this labour lens to sex workers' occupational safety strategies enables vital acknowledgement of their expertise and active participation in shaping the organization of their labour and filtering their clients (similarly to other small business owners), which is rendered even more critical by end-demand criminalization which has been shown to undermine sex worker and client communications and screening $(29,31-33)$. The use of this labour lens also affirms sex workers' extensive advocacy efforts to resist against reductive frames of passive victimization, towards enhancing their rights $(12,37,62,63)$.

Interactions between seeing mostly regulars and work environment on workplace sexual violence and client condom refusal

In additive interaction models, the protective effect of seeing mostly pre-screened regulars on workplace sexual violence and client condom refusal was most significant for participants working in

Page $15 / 25$ 
outdoor/informal indoor spaces, suggesting that under criminalized conditions, sex workers may see prevetted regulars to enhance their occupational safety in more precarious workspaces. The reduced odds of sexual violence and condom refusal for participants who worked in formal indoor venues whether they saw mostly regulars or not is consistent with epidemiological and qualitative evidence that managed indoor settings often offer crucial workplace protections to sex workers $(1,15,37)$. Occupational safety supports in formal indoor venues can include security cameras; sexual health resources (i.e., education/condoms/lubricants); and the presence of venue managers, security, receptionists, and other sex workers to screen clients and monitor the space $(5,11,37,46,61,64,65)$. A Canadian study found working in managed indoor venues to be strongly associated with reduced HIV and STI prevalence and enhanced condom use among sex workers(66). Despite the criminalization of third parties under enddemand laws in Canada and elsewhere, screening clients, intervening in and de-escalating conflict, and removing violent aggressors have been cited as critical roles of managers/security in indoor venues, which contribute vital oversight within the work environment and enhance sex workers' physical and psychological safety $(5,6,37,50,67)$. As our previous research found that sex workers who saw mostly regulars had lower odds of accessing third party (i.e., venue manager, security) support(47), our findings suggest that ensuring that sex workers can engage third parties to assist in the labour of screening/vetting clients if they choose may enable sex workers to see more one-time clients. Our results and existing evidence suggest that working in formal indoor venues with security and screening supports may alleviate sex workers' need to rely on regular, pre-vetted clients in order to work safely in criminalized conditions.

\section{Policy implications}

In a setting where sex work is policed and clients are criminalized, our results highlight protective effects of seeing mostly pre-screened regulars, underscoring a need for policies which enable sex workers to structure their labour according to their own preferences to ensure optimal occupational health. The ability to screen and see new clients is critical for many sex workers' income security - as it is for other small business owners - and should not present health or safety risks. Our findings contribute to a body of evidence demonstrating that sexual violence and HIV/STI exposure in sex work interactions are not a result of clients being unilaterally predatory, but are shaped by broader structural determinants including criminalization, punitive policing, work environments $(1,2,4,30)$, and misogyny and racism which impact both clients' and police's interactions with sex workers $(11,49,60,62)$. Across diverse settings, client criminalization has been shown to create greater pressure to accept clients' terms, undermine sex workers' negotiating power for condom use, and heighten their vulnerability to workplace sexual violence $(9,29,32)$, highlighting how the structural violence of denying labour rights and protections to sex workers enhances workplace violence and rights violations against them.

Our study identified increased odds of seeing mostly pre-screened, regular clients (as opposed to one-time clients) post-end demand law reforms. This likely reflects the reality that under exacerbated criminalization which renders client screening more difficult, more sex workers are choosing to see clients who are pre-vetted and pre-screened. This finding is consistent with emerging evidence from Europe and 
Canada showing that end-demand criminalization has undermined sex workers' ability to screen new clients $(29,32,38,44)$, as clients are more hesitant to provide personal information(29, 31-33) and third parties are criminalized for assisting sex workers with screening(37). When Canada's previous sex work laws were ruled unconstitutional in 2013, the Supreme Court of Canada determined that screening is one of the most significant ways that sex workers are able to protect themselves from potentially violent or undesirable clients(68). However, under end-demand legislation implemented in 2014, $25 \%$ of sex workers reported reduced ability to screen and negotiate with clients(38). In another study involving clients, clients explicitly cited only seeing sex workers they had seen before and giving the least screening information possible to un-vetted sex workers as strategies to avoid potential criminal charges(44). This evidence and our findings suggest that both sex workers and clients may be prioritizing seeing pre-vetted individuals that they have seen before to mitigate the harms introduced by end-demand laws. Rather than leaving sex workers solely responsible for alleviating the structural vulnerability engendered by criminalization, legislative efforts to enhance their safety should dismantle all restrictive policies (i.e., client and third party criminalization) so that sex workers may organize their labour to create optimal conditions for occupational health. The full decriminalization of sex work would remove existing structural barriers to client screening processes, facilitating this vetting for sex workers across diverse work environments (whether they prefer to see mostly regulars or new clients $(69,70)$ ) and advancing sex workers' labour and human rights.

Strengths and limitations

This study relies on observational data which cannot be used to infer causality; additionally, our analyses rely on self-reported data which may be subject to recall, social desirability, or misclassification biases. However, our frontline staff includes experiential (current/former sex workers) and community-based staff with deep experience in building rapport with participants across interview and outreach activities, which is likely to mitigate social desirability bias. A strength of this study is its nuanced focus on sex workers' agency and expertise, moving beyond more risk-oriented framings of past research pertaining to sex work clients. This includes the use of interaction models to further scrutinize variations in the relationship between seeing regulars and sexual violence and condom refusal outcomes across diverse work environments, which was informed by community feedback on preliminary results. A limitation is that our additive interaction term used a binary variable for work environment (i.e., formal indoor venue vs. outdoor or informal indoor space). While there are critical differences between outdoor and informal indoor workspaces, we grouped these due to the complexity of an additive interaction term with six categories. Though we hypothesized primary differences would be among formal indoor sex workers, we may have limited power to detect these differences due to the relatively small number of formal indoor workers who saw mostly regulars, and the non-significance of these results should be interpreted with caution. Further research is recommended to explore potential differences in seeing regular clients among sex workers working in street-based and diverse informal indoor spaces, ranging from private apartments to clients' places to supportive housing settings. 


\section{Conclusions}

Our study identified associations between seeing pre-screened regular clients and decreased odds of workplace sexual violence and client condom refusal, suggesting that within criminalized settings and precarious work environments which render client screening increasingly difficult, sex workers may see mostly regulars to enhance safety and sexual health, including condom use. Particularly amid the evolving COVID-19 pandemic, sex workers' ability to see regular clients may represent an important occupational health strategy which should be supported at legislative levels by dismantling client criminalization which undermines sex workers' screening strategies and agency. It is imperative that policy decisions on sex work regulation are based on empirical data about sex worker-client interactions rather than inaccurate misconceptions. While our findings suggest that sex workers are seeing prescreened regulars to aid in mitigating the structural vulnerability engendered by criminalization, it's unacceptable that current sex work laws undermine sex workers' ability to work safely. Legislative efforts to promote sex workers' occupational safety including HIV/STI prevention should target violence and coercion explicitly rather than adults engaging in consensual sex service exchange, as also recommended by international policy institutions including UNAIDS and Amnesty International $(71,72)$. The full decriminalization of sex work, including removal of end-demand client and third party criminalization, is necessary to enable sex workers to communicate with clients, screen clients, and organize their work according to their needs, towards HIV/STI prevention and the full achievement of sex workers' labour and human rights.

\section{Abbreviations}

\begin{tabular}{|ll|}
\hline AESHA & An Evaluation of Sex Workers Health Access \\
\hline GEE & Generalized estimating equations \\
HCV & Hepatitis C virus \\
HIV & Human immunodeficiency virus \\
IQR & Inter-quartile range \\
STI & Sexually transmitted infection \\
\hline
\end{tabular}

\section{Declarations}

\section{Compliance with ethical standards}

Approval provided by the Providence Health Care/University of British Columbia and Simon Fraser University Research Ethics Boards. REB number H09-02803. All research methods were performed in accordance with all relevant University of British Columbia and Simon Fraser University REB guidelines and regulations. 


\section{Consent to participate}

All participants provided written informed consent.

\section{Consent for publication}

Not applicable.

\section{Availability of data and materials}

Due to our ethical and legal requirements related to protecting participant privacy and current ethical institutional approvals, all relevant data are available upon request pending ethical approval. Please submit all requests to initiate the data access process to the corresponding author.

\section{Competing interests}

Disclosures:

- The authors have no relevant financial or non-financial interests to disclose.

- The authors have no conflicts of interest to declare that are relevant to the content of this article.

- All authors certify that they have no affiliations with or involvement in any organization or entity with any financial interest or non-financial interest in the subject matter or materials discussed in this manuscript.

- The authors have no financial or proprietary interests in any material discussed in this article.

\section{Funding}

This research was supported by grants from the US National Institutes of Health (R01DA028648) and Canadian Institutes of Health Research (165855). KS is partially supported by a Canada Research Chair in Global Sexual Health and NIH. SG is partially supported by a CIHR New Investigator Award and NIH.

\section{Author contributions}

B. McBride and S. M. Goldenberg conceptualized and designed the study. B. McBride, S. M.

Goldenberg, and M. Braschel contributed to the interpretation and analysis of data. B. McBride prepared the first draft of the article. K. Shannon, J. Pearson, A. Krusi, M. Braschel and S. M. Goldenberg contributed critical feedback and edits to article drafts. All authors approved the final article.

\section{Acknowledgments}

We thank all those who contributed their time and expertise to this project, particularly participants, AESHA community advisory board members and partner agencies, and the AESHA team, including: Kate Lumsdon, Jennifer McDermid, Christie Ngozi Gabriel, Natasha Feuchuk, Jennifer Morris, Shannon 
Bundock, Alka Murphy, Sylvia Machat, Tina Beaulieu, Lois Luo, Minshu Mo, Sherry Wu, Zoe Hassall and Emma Kuntz. We also thank Peter Vann, Megan Bobetsis, Arveen Kaur, and Rayka Kumru for their research and administrative support.

\section{References}

1. Shannon K, Strathdee S, Goldenberg SM, Duff P, Mwangi P, Rusakova M, et al. Global epidemiology of HIV among female sex workers: Influence of structural determinants. Lancet. 2015;385(9962):5571.

2. Decker MR, Crago AL, Chu SKH, Sherman SG, Seshu MS, Buthelezi K, et al. Human rights violations against sex workers: Burden and effect on HIV. Lancet [Internet]. 2015;385(9963):186-99. Available from: http://dx.doi.org/10.1016/S0140-6736(14)60800-X

3. Platt L, Grenfell P, Meiksin R, Elmes J, Sherman SG, Sanders T, et al. Associations between sex work laws and sex workers' health: A systematic review and meta-analysis of quantitative and qualitative studies. Tsai AC, editor. PLOS Med [Internet]. 2018 Dec 11 [cited 2019 Feb 15];15(12):e1002680. Available from: http://dx.plos.org/10.1371/journal.pmed.1002680

4. Deering KN, Amin A, Shoveller JA, Nesbitt A, Garcia-Moreno C, Duff P, et al. A systematic review of the global magnitude and drivers of violence against sex workers. Am J Public Health. 2014;104(5):e4254.

5. Yi H, Zheng T, Wan Y, Mantell JE, Park M, Csete J. Occupational safety and HIV risk among female sex workers in China: A mixed-methods analysis of sex-work harms and mommies. Glob Public Health [Internet]. 2012 Sep;7(8):840-55. Available from: http://www.tandfonline.com/doi/abs/10.1080/17441692.2012.662991

6. Duff P, Shoveller J, Dobrer S, Ogilvie G, Montaner JS, Chettiar J, et al. The relationship between social, policy and physical venue features and social cohesion on condom use for pregnancy prevention among sex workers: A safer indoor work environment scale. J Epidemiol Community Health. 2016;69(7):666-72.

7. Lyons CE, Grosso A, Drame FM, Ketende S, Diouf D, Ba I, et al. Physical and Sexual Violence Affecting Female Sex Workers in Abidjan, Côte d'Ivoire: Prevalence, and the Relationship with the Work Environment, HIV, and Access to Health Services. J Acquir Immune Defic Syndr [Internet]. 2017 May 1 [cited 2017 Sep 6];75(1):9-17. Available from: http://insights.ovid.com/crossref?an=00126334201705010-00002

8. NSWP. The Impact of Criminalisation on Sex Workers' Vulnerability to HIV and Violence [Internet]. 2017. Available from: http://www.nswp.org/sites/nswp.org/files/impact_of_criminalisation_pb_prf01.pdf

9. NSWP. The Impact of "End Demand" Legislation on Women Sex Workers. 2018.

10. NSWP. Global Mapping of Sex Work Laws [Internet]. 2020 [cited 2021 Feb 16]. Available from: https://www.nswp.org/sex-work-laws-map?colour_value[0]=2 
11. O'Doherty T. Victimization in off-street sex industry work. Violence Against Women. 2011;17(51):944-63.

12. Atchison C, Oliffe J, Murphy A, Porth K, Steele V, Davis S, et al. Recommendations from the Off-Street Sex Industry in Vancouver. 2016;(December).

13. Shannon K, Csete J. Violence, Condom Negotiation, and HIV/STI Risk Among Sex Workers. JAMA [Internet]. 2010 Aug 4 [cited 2018 Aug 14];304(5):573. Available from:

http://jama.jamanetwork.com/article.aspx?doi=10.1001/jama.2010.1090

14. Krüsi A, Pacey K, Bird L, Taylor C, Chettiar J, Allan S, et al. Criminalisation of clients: reproducing vulnerabilities for violence and poor health among street-based sex workers in Canada-a qualitative study. BMJ Open [Internet]. 2014;4(6):e005191. Available from:

http://bmjopen.bmj.com/content/4/6/e005191.abstract

15. Goldenberg SM, Duff P, Krusi A. Work environments and HIV prevention: a qualitative review and meta-synthesis of sex worker narratives. BMC Public Health [Internet]. 2015;15(1):1241. Available from: http://www.biomedcentral.com/1471-2458/15/1241

16. Duff P, Birungi J, Dobrer S, Akello M, Muzaaya G, Shannon K. Social and structural factors increase inconsistent condom use by sex workers' one-time and regular clients in Northern Uganda. AIDS Care [Internet]. 2018 Jun 3 [cited 2018 Sep 20];30(6):751-9. Available from:

https://www.tandfonline.com/doi/full/10.1080/09540121.2017.1394966

17. Decker MR, Pearson E, Illangasekare S, Clark E, Sherman SG. Violence against women in sex work and HIV risk implications differ qualitatively by perpetrator. BMC Public Health [Internet]. 2013;13:876. Available from: http://ovidsp.ovid.com/ovidweb.cgi?

$\mathrm{T}=\mathrm{JS} \& \mathrm{PAGE}=$ reference\&D$=$ emed $15 \& \mathrm{NEWS}=\mathrm{N} \& A \mathrm{~N}=604576750$

18. Gilchrist G, Taylor A, Goldberg D, Mackie C, Denovan A, Green ST. Behavioural and lifestyle study of women using a drop-in centre for female street sex workers in Glasgow, Scotland: A 10 year comparative study. Addict Res Theory [Internet]. 2001 [cited 2020 Oct 13];9(1):43-58. Available from: https://www.tandfonline.com/doi/abs/10.3109/16066350109141771

19. Milrod C, Monto MA. The Hobbyist and the Girlfriend Experience: Behaviors and Preferences of Male Customers of Internet Sexual Service Providers. Deviant Behav [Internet]. 2012 Nov;33(10):792-810. Available from: http://www.tandfonline.com/doi/abs/10.1080/01639625.2012.707502

20. Van Meyl K. On the Separation of Personal and Professional: Sex, Work, Law, the Girlfriend Experience, and the Interpersonal Relationships of Independent Escorts by Affairs in partial fulfillment of the requirements for the degree of Master of Arts. 2014;

21. Stoebenau K, Hindin MJ, Nathanson CA, Rakotoarison PG, Razafintsalama V. “... But Then He Became My Sipa ": The Implications of Relationship Fluidity for Condom Use Among Women Sex Workers in Antananarivo, Madagascar. Am J Public Health [Internet]. 2009 May;99(5):811-9. Available from: http://ajph.aphapublications.org/doi/10.2105/AJPH.2007.118422

22. Basuki E, Wolffers I, Devillé W, Erlaini N, Luhpuri D, Hargono R, et al. Reasons For Not Using Condoms Among Female Sex Workers in Indonesia. AIDS Educ Prev [Internet]. 2002 Apr 2;14(2):102-16. 
Available from: http://guilfordjournals.com/doi/10.1521/aeap.14.2.102.23901

23. Ghimire L, Smith WCS, van Teijlingen ER, Dahal R, Luitel NP. Reasons for non- use of condoms and self- efficacy among female sex workers: a qualitative study in Nepal. BMC Womens Health [Internet]. 2011 Dec 26;11(1):42. Available from:

https://bmcwomenshealth.biomedcentral.com/articles/10.1186/1472-6874-11-42

24. Okeowo A. The Fragile Existence of Sex Workers During the Pandemic. The New Yorker [Internet]. 2020 May 21 [cited 2021 Feb 23]; Available from: https://www.newyorker.com/news/news-desk/thefragile-existence-of-sex-workers-during-the-pandemic

25. UNAIDS. COVID-19 responses must uphold and protect the human rights of sex workers [Internet]. 2020 [cited 2021 Feb 23]. Available from:

https://www.unaids.org/en/resources/presscentre/featurestories/2020/april/20200424_sex-work

26. Preston P, Brown-Hart AD. John court: Comparison of characteristics, sexual behavior and sexual attitudes of clients of prostitutes. J Ethn Crim Justice. 2006;

27. Nordic Model Now. What is the Nordic Model? - Nordic Model Now! [Internet]. 2015 [cited 2019 Aug 19]. Available from: https://nordicmodelnow.org/what-is-the-nordic-model/

28. Klambauer E. Policing roulette: Sex workers' perception of encounters with police officers in the indoor and outdoor sector in England. Criminol Crim Justice. 2018;18(3):255-72.

29. Levy J, Jakobsson P. Sweden's abolitionist discourse and law: Effects on the dynamics of Swedish sex work and on the lives of Sweden's sex workers. Criminol Crim Justice. 2014;14(5):593-607.

30. Footer KHA, Silberzahn BE, Tormohlen KN, Sherman SG. Policing practices as a structural determinant for HIV among sex workers: A systematic review of empirical findings. Journal of the International AIDS Society. 2016.

31. Jakobsson P. En annan horisonts - Exarbete och hiv/sti-prevention ur ett peer-perspektiv. 2013.

32. Le Bail H, Giametta C. What do sex workers think about the French prostitution act? 2018;(April). Available from: https://www.medecinsdumonde.org/sites/default/files/ENGLISH-Synthèse-Rapportprostitution-BD.PDF

33. McDermid J, Murphy A, McBride B, Mo M, Goldenberg SM, Shannon K, et al. The impact of enddemand criminalization on occupational health and experiences of violence among sex workers in Vancouver, Canada. In: APHA's 2020 VIRTUAL Annual Meeting and Expo. American Public Health Association; 2020.

34. Parliament of Canada. C-36 (41-2) - Royal Assent - Protection of Communities and Exploited Persons Act [Internet]. Ottawa: Parliament of Canada; 2014. Available from: http://www.parl.ca/DocumentViewer/en/41-2/bill/C-36/royal-assent/page-33\#3

35. Galbally P. Playing the victim: A critical analysis of Canada's Bill C-36 from an international human rights perspective. Melb J Int Law. 2016;17:1-36.

36. Department of Justice. Prostitution Criminal Law Reform: Bill C-36, the Protection of Communities and Exploited Persons Act [Internet]. 2014 [cited 2018 Nov 29]. Available from: https://www.justice.gc.ca/eng/rp-pr/other-autre/c36fs_fi/c36fs_fi_eng.pdf 
37. McBride B, Shannon K, Murphy A, Wu S, Erickson M, Goldenberg SM, et al. Harms of third party criminalisation under end-demand legislation: undermining sex workers' safety and rights. Cult Heal Sex [Internet]. 2020;0(0):1-17. Available from: https://doi.org/10.1080/13691058.2020.1767305

38. Machat S, Shannon K, Braschel M, Moreheart S, Goldenberg SM. Sex workers' experiences and occupational conditions post-implementation of end-demand criminalization in Metro Vancouver, Canada. Can J Public Heal [Internet]. 2019 Oct 10;110(5):575-83. Available from: http://link.springer.com/10.17269/s41997-019-00226-z

39. BC Centre for Disease Control. Guidance for sex workers [Internet]. Vancouver; 2020. Available from: http://www.bccdc.ca/Health-Info-Site/Documents/COVID19_SexWorkersGuidance-poster.pdf

40. Shannon K, Bright V, Allinott S, Alexson D, Gibson K, Tyndall MW. Community-based HIV prevention research among substance-using women in survival sex work: the Maka Project Partnership. Harm Reduct J [Internet]. 2007 Dec 8 [cited 2017 Apr 3];4:20. Available from: http://www.ncbi.nlm.nih.gov/pubmed/18067670

41. Harris PA, Taylor R, Thielke R, Payne J, Gonzalez N, Conde JG. Research electronic data capture (REDCap)-A metadata-driven methodology and workflow process for providing translational research informatics support. J Biomed Inform. 2009;

42. Maldonado G, Greenland S. Simulation Study of Confounder-Selection Strategies. Am J Epidemiol [Internet]. 1993 Dec 1 [cited 2017 Apr 3];138(11):923-36. Available from: https://academic.oup.com/aje/article/122634/Simulation

43. SWAN Vancouver Society. Im/migrant sex workers, myths and misconceptions: realities of the antitrafficked [Internet]. Vancouver; 2015 [cited 2017 Apr 2]. Available from: http://swanvancouver.ca/wpcontent/uploads/2014/01/Realities-of-the-Anti-Trafficked.pdf

44. Sterling A, van der Meulen E. "We Are Not Criminals": Sex Work Clients in Canada and the Constitution of Risk Knowledge. Can J Law Soc / Rev Can Droit Société [Internet]. 2018 Dec 25;33(3):291-308. Available from: https://www.cambridge.org/core/product/identifier/S0829320118000133/type/journal_article

45. Lam E. Survey on Toronto Holistic Practitioners' Experiences with Bylaw Enforcement and Police [Internet]. 2018. Available from: https://576a91ec-4a76-459b-8d054ebbf42a0a7e.filesusr.com/ugd/5bd754_6d780ceba3cb4f6c85de4d3e9e0b7475.pdf

46. Semple SJ, Strathdee SA, Srikrishnan AK, Solomon S, Patterson TL. Social and behavioral characteristics of gharwalis who operate brothels in the Ganga-Jamuna area of Nagpur, India. AIDS Care [Internet]. 2013 Apr [cited 2017 Oct 24];25(4):438-42. Available from: http://www.tandfonline.com/doi/abs/10.1080/09540121.2012.712663

47. McBride B, Goldenberg SM, Murphy A, Wu S, Braschel M, Krüsi A, et al. Third Parties (Venue Owners, Managers, Security, etc.) and Access to Occupational Health and Safety Among Sex Workers in a Canadian Setting: 2010-2016. Am J Public Health. 2019 Mar;e1-7.

48. Goldenberg SM, Rocha Jiménez T, Brouwer KC, Morales Miranda S, Silverman JG. Influence of indoor work environments on health, safety, and human rights among migrant sex workers at the 
Guatemala-Mexico Border: a call for occupational health and safety interventions. BMC Int Health Hum Rights [Internet]. 2018 Dec 2 [cited 2019 Feb 15];18(1):9. Available from:

https://bmcinthealthhumrights.biomedcentral.com/articles/10.1186/s12914-018-0149-3

49. Lam E. Inspection, policing, and racism : How municipal by-laws endanger the lives of Chinese sex workers in Toronto. 2016;75:87-112.

50. Goldenberg SM, Krusi A, Zhang E, Chettiar J, Shannon K. Structural Determinants of Health among Im/Migrants in the Indoor Sex Industry. PLoS One. 2017;1-19.

51. Bernstein E. Temporarily Yours: Intimacy, Authenticity, and the Commerce of Sex [Internet]. Chicago: University of Chicago Press; 2007 [cited 2021 Mar 31]. Available from:

https://press.uchicago.edu/ucp/books/book/chicago/T/bo5298935.html

52. Murray L, Moreno L, Rosario S, Ellen J, Sweat M, Kerrigan D. The Role of Relationship Intimacy in Consistent Condom Use Among Female Sex Workers and Their Regular Paying Partners in the Dominican Republic. AIDS Behav [Internet]. 2007 Apr 3;11(3):463-70. Available from: http://link.springer.com/10.1007/s10461-006-9184-5

53. Duff P, Birungi J, Dobrer S, Akello M, Muzaaya G, Shannon K. Social and structural factors increase inconsistent condom use by sex workers' one-time and regular clients in Northern Uganda. AIDS Care [Internet]. 2018 Jun 3;30(6):751-9. Available from:

https://www.tandfonline.com/doi/full/10.1080/09540121.2017.1394966

54. Kolar K, Atchison C, Bungay V. Sexual safety practices of massage parlor- based sex workers and their clients. AIDS Care; Psychol Socio-medical Asp AIDS/HIV. 2014;26(9):1100-4.

55. Giusta M Della, Di Tommaso ML, Shima I, Strøm S. What money buys: Clients of street sex workers in the US. Appl Econ. 2009;41(18):2261-77.

56. Monto MA, McRee N. A comparison of the male customers of female street prostitutes with national samples of men. Int J Offender Ther Comp Criminol [Internet]. 2005 Oct [cited $2021 \mathrm{Feb}$ 16];49(5):505-29. Available from: https://pubmed.ncbi.nlm.nih.gov/16260480/

57. Sawyer S, Metz ME, Hinds JD, Brucker RA. Attitudes towards prostitution among males: A "consumers" report"." Curr Psychol [Internet]. 2001 [cited 2021 Feb 16];20(4):363-76. Available from: https://link.springer.com/article/10.1007/s12144-001-1018-z

58. Monto MA, Milrod C. Ordinary or peculiar men? Comparing the customers of prostitutes with a nationally representative sample of men. Int J Offender Ther Comp Criminol. 2014;

59. Monto MA. Female Prostitution, Customers, and Violence. Violence Against Women. 2004.

60. Brents BG, Yamashita T, Spivak AL, Venger O, Parreira C, Lanti A. Are Men Who Pay for Sex Sexist? Masculinity and Client Attitudes Toward Gender Role Equality in Different Prostitution Markets. Men Masc. 2020;(July).

61. Sanders T, Campbell R. Designing out vulnerability, building in respect : violence, safety and sex work policy. Br J Sociol. 2007;58(1):1-19.

62. SWAN Vancouver Society. Im/migrant sex workers, myths and misconceptions - realities of the antitrafficked [Internet]. Vancouver; 2020. Available from: https://3ef32e5e-964e-4a01-a2dc- 
2292a5000739.filesusr.com/ugd/3a120f_8cf163d66eb345d385b254eb91d72cd2.pdf

63. Canadian Alliance for Sex Work Law Reform. Meaningful participation of sex workers in policy [Internet]. 2019. Available from: https://sexworklawreform.com/meaningful-participation-of-sexworkers-in-policy/

64. Bruckert C, Law T. Beyond Pimps, Procurers and Parasites: Mapping Third Parties in the Incall/Outcall Sex Industry. Ottawa; 2013.

65. Goldenberg SM, Duff P, Krusi A. Work environments and HIV prevention: a qualitative review and meta-synthesis of sex worker narratives. BMC Public Health [Internet]. 2015 Dec 16 [cited 2017 Oct 6];15(1):1241. Available from: http://www.biomedcentral.com/1471-2458/15/1241

66. Anderson S, Shannon K, Li J, Lee Y, Chettiar J, Goldenberg S, et al. Condoms and sexual health education as evidence: impact of criminalization of in-call venues and managers on migrant sex workers access to HIV/STI prevention in a Canadian setting. BMC Int Health Hum Rights. 2016;16(1):1-10.

67. Casey L, McCarthy B, Phillips R, Benoit C, Jansson M, Magnus S, et al. Managing conflict: An examination of three-way alliances in Canadian escort and massage businesses. In: Third Party Sex Work and Pimps in the Age of Anti-Trafficking. 2017.

68. Supreme Court of Canada. Canada (Attorney General) v. Bedford - SCC Cases [Internet]. 2013. Available from: https://scc-csc.lexum.com/scc-csc/scc-csc/en/item/13389/index.do

69. Armstrong L. Screening clients in a decriminalised street-based sex industry: Insights into the experiences of New Zealand sex workers. Aust New Zeal J Criminol. 2014;47(2):207-22.

70. NSWP. The Impact of 'End Demand' Legislation on Women Sex Workers. 2018; Available from: http://www.nswp.org/sites/nswp.org/files/pb_impact_of_end_demand_on_women_sws_nswp__2018.pdf

71. UNAIDS. The Gap Report 2014 - Sex workers [Internet]. Geneva; 2014 [cited 2017 Apr 4]. Available from: http://www.unaids.org/sites/default/files/media_asset/06_Sexworkers.pdf

72. Amnesty International. Decision on State Obligations To Respect, Protect, and Fulfil the Human Rights of Sex Workers. Int Counc Decis [Internet]. 2016;(May):9-10. Available from: https://www.amnesty.org/en/policy-on-state-obligations-to-respect-protect-and-fulfil-the-humanrights-of-sex-workers/ 